\title{
Replay-peak attention chart: A performance measure for improving online video lecture design
}

\author{
Nitza Geri, The Open University of Israel, Israel, nitzage@openu.ac.il \\ Orna Kopolovich, Holon Institute of Technology, Israel, ornak@hit.ac.il \\ Amir Winer, The Open University of Israel, Israel, amirwi@openu.ac.il
}

\begin{abstract}
The ability to replay selected video segments is a major advantage of online video lectures. Replay is a learning instance that reflects active engagement. This paper develops the 'replay-peak attention chart' as a new performance measure of learner's attention, based on the control chart concept, which is used for Statistical Process Control (SPC) in operations management. This study follows the design science research paradigm and employs a mixed methods methodology, combining quantitative learning analytics with qualitative analysis of notable segment replay instances by viewers of online video lectures. An analysis of a successful Massive Open Online Course (MOOC), titled "Negotiation Management" provides a proof-of-concept for the replaypeak attention chart, as a visual heuristic tool for identifying notable learning instances. The MOOC includes Educational Entertainment (edutainment) in the form of negotiation simulations which are presented as sitcoms and are meant to increase learner engagement. From an attention economy perspective, the replay-peak attention chart may help instructors and designers to focus their limited attention resources on segments of online video lecture sessions that may require pedagogical interventions. This paper critically discusses the replay-peak attention chart conceptualization and its initial proof-of-concept. It suggests future research directions for substantiating the replay-peak attention chart and investigating the effect of edutainment on online learning. The replay-peak attention chart is a dynamic descriptive performance measure, which has a promising potential to improve the design of effective online video lectures as an e-learning resource.
\end{abstract}

Keywords: Replay-peak attention chart, online video lectures, attention economy, learning analytics, learning design, "Negotiation Management" MOOC, edutainment.

\section{Introduction}

Online video lectures are rapidly becoming a popular means for e-learning. One of the advantages of an online video lecture over a face-to-face lecture is the ability of the learner to replay any segment of the video. Replay allows the learner to exercise difficult issues, to pause and repeat important content, and to overcome occasional attention distractions. Visual analyses of the replay attribute, along with emerging Learning Analytics (LA) tools, provide lecturers with novel opportunities to intervene and provide timely support to their students. Furthermore, these learning patterns allow lecturers, learning designers and content publishers to constantly improve the effectiveness of their online teaching and digital courseware. 
Current LA research is mainly focused on forecasting student performance and retention, while there is scant research on the effectiveness of LA interventions (Larrabee Sønderlund et al., 2019). Furthermore, few studies investigate video replay. Martin et al. (2018) examined replay of whole video lectures in laboratory settings, and found that re-watching the same video lecture, increased mind-wandering, rather than improving the ability to memorize the lecture material. Contrarily, our study examines in-video replays of short video content that reflects genuine and authentic internal motivation for learning. Furthermore, our study investigates real-life settings, where the learners demonstrate attention patterns on a short and specific content. These replay instances reflect student interactions with video content, which is another important issue that has been scarcely studied (Li et al., 2015).

This study adopts an attention economy (Davenport \& Beck, 2001; Geri \& Geri, 2011) approach to identify learner attention patterns, as reflected in replays of online video lecture segments. As an applied research, our goal is to provide practical insight to the effective design of online video lectures. The first research objective is to design an effective performance measure for identifying notable learning instances. This paper develops the notion of a 'replay-peak attention chart', as a new performance measure, which is based on operations management research and practice, particularly on Statistical Process Control (SPC).

The second research objective is to provide a proof-of-concept of the replay-peak attention chart performance measure. Li et al. (2015) presented the obvious and common context of replays as reflecting higher levels of content difficulty. We suggest the replay-peak attention chart as a comprehensive methodology for attention management, which may be used to identify tacit instances of learning. Hence, to avoid the overshadowing difficulty dimension, we chose a Massive Open Online Course (MOOC), titled "Negotiation Management", which is highly relevant to real life situations. Hence, the MOOC does not contain difficult content. Furthermore, in order to increase learner engagement, we chose a MOOC that includes Educational Entertainment (edutainment) video content in the form of negotiation simulations which are presented as sitcoms. The MOOC is further described in the Methodology Section.

This study is important because replay is an active learning action that reflects learning engagement. Replay of certain contents should be encouraged actively by the teaching staff, whereas the need for reinforcement may be implied by unexpected replays of some other video content. Hence, understanding replay patterns may improve both learning design and active teaching. The replay-peak attention chart may provide lecturers with important feedback and focus their limited attention resources on specific parts of online video lecture sessions that may require pedagogical interventions.

Furthermore, organizations, governments, and higher education institutions, invest considerable resources, financial funds as well as time of instructors and designers, in the production and maintenance of online video lectures. Better understanding of video lecture replay patterns may provide important insights for increasing the effectiveness of online video lectures as an e-learning resource. 


\section{Theoretical Background}

\section{Attention, Learning Engagement, and Edutainment}

Learner engagement is a critical element for knowledge construction in e-learning environments (Koohang et al., 2014). Retaining the attention of learners is a well-known challenge of e-learning (Levy, 2007). Furthermore, recent learning analytics studies indicate that learning design activities have major influence on student retention (Geri et al., 2017; Rienties \& Toetenel, 2016).

The use of diverse forms of entertainment, such as games, storytelling, songs, riddles, theatre plays, and simulation, as an engaging means of education that retains learner attention is as old as mankind. In the modern context of mass media and movies, Walt Disney was one of the most renowned champions of edutainment in the $20^{\text {th }}$ century (Van Riper, 2011). Nowadays, there are ample opportunities for integrating engaging videos, animations, simulations and infographics as open educational resources. Moreover, instructors who design asynchronous online video lectures are no longer limited to using video clips that were created by others. A plethora of authoring tools allows faculty and educational technology experts, to easily create original interactive learning objects. These learning resources are expected to promote student engagement and learning (Makarius, 2017). Nevertheless, there are major concerns about using video-based edutainment resources, such as TV series, short cinematic segments, TED talks that were not originally designed for educational purposes. Moreover, critics highlight the risk of hidden branded contents within video-based content that might hamper the original pedagogical intent of using them as edutainment resources (Moe, 2015). Fortunately, affordable internal video production capabilities allow faculty members to create their own video-based edutainment content.

Okan (2003) questioned the balance of entertainment and education and argues that edutainment design should be based on constructivist learning theory, as well as educational technology and educational psychology research. Nowadays, maintaining learner attention is harder than ever, as attention is considered the scarcest resource (Davenport \& Beck, 2001). Therefore, edutainment seems to be an important means to capture and extend learner attention and consequently, to increase their engagement. Replays of online video lecture segments represent higher levels of viewer attention. However, given the risk of limiting our attention solely to edutainment video segments, our research addresses the challenge of developing performance measures that reflect notable learning instances.

\section{Performance Measurement}

Learning analytics provide numerous opportunities for performance measurement of various aspects of teaching and learning (Ferguson, 2012; Henderikx et al., 2017; Jørnø \& Gynther, 2018; Kalz et al., 2015; Lockyer et al., 2013). Alongside with the desired improvement cycle, LA pose dramatic ethical concerns, pedagogical challenges and organizational consideration, given the multiplicity of conflicting stakeholders (Winer \& Geri, 2019). As an emerging interdisciplinary field of study, learning analytics may gain important insights from business administration studies. Particularly, this study relies on proven operations management practices that have been established and refined over more than a century. The operations management field provides us with the theoretical concepts of what constitutes effective performance measures, as well as how 
to monitor processes and control them (Ronen \& Pass, 2007; Ronen et al., 2006). Appropriate performance measures should have the following properties (Geri \& Ronen, 2005): Relevant for promoting organizational effectiveness; Understandable by the users, specifically by means of how measures are calculated and what they mean, as opposed to a 'black-box' model, created by sophisticated machine-learning models (Pasquale, 2015); Simple and easy to apply; and, Preferably, the measures should be based on existing data.

SPC is a well-known quality control methodology for monitoring and controlling processes. SPC was initially developed by Shewhart $(1926,1986)$ at Bell Laboratories. Control charts are among the main graphical performance measurement tools of SPC. Control charts were suggested by Shewhart (1926), and became prevalent due to Deming (1982), who utilized them to recover the Japanese Manufacturing industry during the 1950s-1960s (Aguayo, 1991). Control charts are based on the assumption that approximately $99.7 \%$ of process observations fluctuate according to the normal distribution and are within three standard deviations (SD) from the average. Thus, the control chart distinguishes the expected variations in the production process (i.e., those within the limits of plus/minus three Standard Deviation (SD) from the average), from measurements outside these limits, suggesting that the process has become unstable, and requires intervention.

SPC in general, including the use of control charts, have some known drawbacks and inaccuracies (Woodall, 2000), such as 'false alarms', occurring when controlled processes have outliers that do not require interventions (Woodall \& Faltin, 2019). Nevertheless, like Deming (1982, 2018), who opposed 'management by the numbers', we regard control charts as a heuristic tool for identifying irregular events that may need intervention.

\section{The Replay-Peak Attention Chart}

Based on the theoretical background concepts reviewed in sub-section "Performance Measurement" above, we suggest using the notion of a replay-peak attention chart performance measure for identifying notable learning instances within online video lectures. We propose the following as an initial definition of a replay-peak:

A replay-peak is a notable video segment that was replayed with 1.3 standard deviations above the average number of segment replays, within a single video lecture.

Figure 1 presents a generic demonstration of the replay-peak attention chart. The selection of 1.3 standard deviations above the average as the cutoff point for performance measurement is an initial suggestion that should be refined in further studies. This $1.3 \mathrm{SD}$ initial cutoff point is based on the assumption that the segment replays within an online video lecture are approximately normally distributed. Therefore, about $90 \%$ of the replays should be below the $1.3 \mathrm{SD}$ upper limit.

In order to demonstrate how to use the replay-peak attention chart for identifying notable learning instances, we highlight seven peak points on the graph presented in Figure 1. The Average line and both the 1.3 SD and -1.3 SD define four chart sections. Points A, B, C, D, and G are all above the average. However, only points $B$ and $G$ are replay-peaks that invite further exploration by the instructors and the designers of the video lectures as notable learning instances. Points A, C, and $\mathrm{D}$ are above the average, but they are within the expected fluctuation of replays. The segments within the range above the average and below the 1.3 SD line, reflect active learning to a lesser 
degree. The replay-peak attention chart focuses on the replay-peaks (e.g. points B \& G in Figure 1) that are extraordinary, while points $\mathrm{E}$ and $\mathrm{F}$ are below the average.

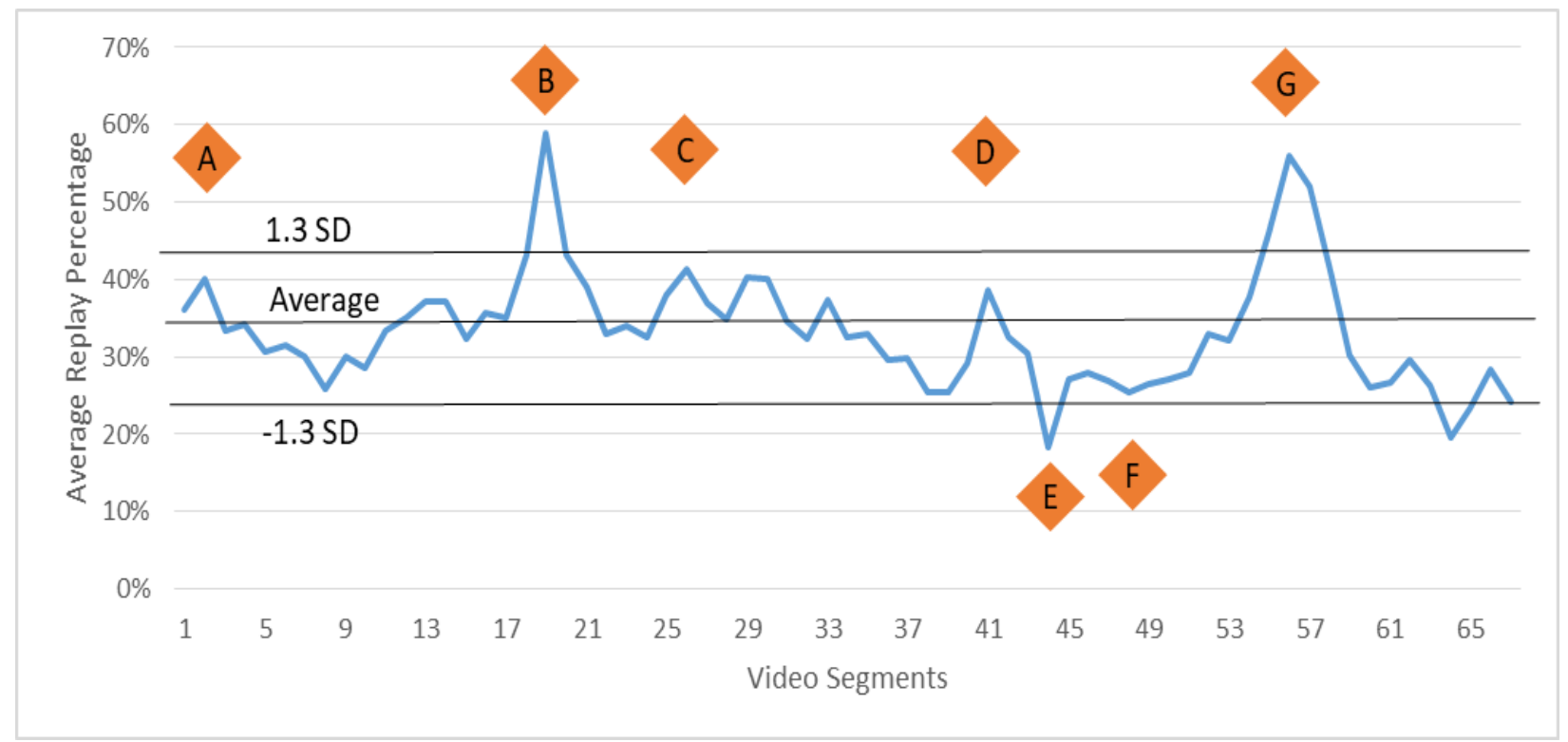

Figure 1. The Replay-Peak Attention Chart

It may be helpful to add a lower limit at minus 1.3 SD to identify irregular points of low replays. As shown in Figure 1, point $\mathrm{E}$ is below the lower limit, and should be further examined. However, point $\mathrm{F}$ is within the expected range. This paper critically examines the suggested replay-peak concept and provides an initial proof-of-concept for the replay-peak attention chart performance measure, by a quantitative and qualitative analysis of a successful MOOC. Hence, the discussion is limited to exceptionally high replays.

It should be noted that the replay-peak attention chart is unlike the conventional control chart concept, which is intended to serve as a heuristic that supports SPC. A conventional controlled process is supposed to fluctuate within the upper and lower limits of the control chart (Shewhart, 1986). When the process goes above or below these limits, it means that it may be out of control. This is an undesirable incident. The process should be checked and if necessary, reparatory measures should be taken to fix the process. However, the replay-peak attention chart is different. It is expected that there will be some replay-peaks that reflect the desired patterns of engaged learners. Nevertheless, as with any process, there may be outlier, such as an exceptionally funny episode within the edutainment part of the video lecture, which will be replayed although its pedagogical value is negligible.

We expect that the replay-peak attention chart performance measure will initially support identifying and highlighting tacit learning events and consequently, provide insights for improving the design of video lectures. Instructors do not need sophisticated learning analytics algorithms to help them identify difficult learning concepts or content-specific skills. These topics can easily be extracted from past achievements, success rates of specific exercises and other learning activities. Instructors are therefore, right to avoid unnecessary technological hype and rely on their common 
sense, intuition, and the support of their peers. Therefore, we also examine the potential of the replay-peak attention chart performance measure to provide instructors with insights beyond the obvious.

\section{Methodology}

Drawing on the design science research approach (Hevner, 2007; Simon, 1996), this pioneering study employs a mixed methods methodology, which combines quantitative learning analytics with qualitative analysis of notable segment replay instances by viewers of online video lectures. This study follows Hevner (2007)'s three cycle view of the design science research paradigm. The relevance cycle identifies the opportunities of replay analysis to improve teaching and learning via online video lectures. The rigor cycle builds the theoretical background, relying on operations management research, as well as learning design (Mor et al., 2015; Mor \& Winters, 2007). Based on the relevance and rigor cycles, the design cycle develops the replay-peak attention chart performance measure, and empirically examines it in the field, using a case study of a "Negotiation Management" MOOC. Furthermore, this study is an action research (Coghlan, 2019; Ellis \& Levy, 2009) since the three researchers are involved in online video lecture design. However, just one of the researchers was involved in creating and teaching the examined MOOC. We shall call her 'the Lecturer'.

\section{The "Negotiation Management" MOOC}

The "Negotiation Management" MOOC was designed in an Edutainment approach (Van Riper, 2011). The MOOC was developed by Orna Kopolovich at the Holon Institute of Technology (HIT), Israel. The development process and the actual instruction of the MOOC are elaborately discussed in Kopolovich (2020), who portrayed the challenges, the dilemmas, the chosen solutions, and their implications. The course is based on a series of mini-case simulations of real-life situations, which are presented as sitcoms. The short video lectures analyze the simulations, using theories, models, and concepts, which are based on the lecturer's practical teaching experience in both higher education and professional training settings. This format is designed to create a strong emotional engagement with the course contents and to motivate students to continue learning.

The target audience of the "Negotiation Management" MOOC includes two main groups: the general public, as lifelong learners, and college students. The general public is the larger group comprising more than $95 \%$ of the registrants (anyone who is 18 years old, or above, may register); and the smaller group includes both undergraduate and graduate students of the college. The college students study in a blended learning model (Taylor et al., 2018), and use the MOOC for pre-class learning as a part of a flipped classroom instructional strategy (O'Flaherty \& Phillips, 2015). However, the data analyzed in this research does not include an indication that would enable to identify which students belong to each one of the two groups. The MOOC was first offered in the Fall of 2018 and has been taught three times already. The first cohort had 3,500 registrants. This study investigated the second cohort (hereafter, Cohort 2) that was offered during the Spring of 2019, in which there were 2,500 registrants. During the third cohort that started in the Fall of 2019, there were more than 5,000 registrants. 
The "Negotiation Management" MOOC that was selected for the proof-of-concept of the replaypeak attention chart performance measure, has three unique characteristics, which on the one hand make it highly appropriate for this research, on the other hand, this uniqueness may impede the generalizability of the findings to other MOOCs, or non-MOOC online video lectures. The first two attributes are the high retention rate and the lack of difficult content. The third distinctive attribute is the edutainment component of the MOOC, which is based on sitcoms. These three attributes are demonstrated in the Results Section.

\section{The Analysis Process}

The first phase of the analysis process was qualitative. Two researchers (i.e., not the Lecturer, who is highly familiar with the course content) randomly watched seven short videos out of 14 videos included in the second (five videos), the fourth (four videos), and the sixth (five videos) units of the course. The two researchers watched the same seven videos. They identified one to five segments within each video that included information or insight, which they perceived learners would like to document and memorize (by writing it down, by watching it again, or by other means). These are termed 'learning instances'. Each researcher identified the learning instances separately. There was full agreement on the learning instances between the two researchers. Next, the researchers compared these learning instances to the actual segment replay-peaks, as recorded by the Learning Management System (LMS). The learning instances were identical to the replaypeaks.

The second phase of the analysis process was quantitative. It began with initial validation of the new replay-peak attention chart performance measure by comparing the replay-peaks of all the short video lectures included in units 2 and 4 of the first and second cohorts. Figure 2 presents a sample comparison of the replay-peak attention chart of video 2 , unit 2, between cohort 1 and cohort 2. As shown in Figure 2, most of the replay-peaks were identical. Thus, these findings corroborate the validity of the replay-peak attention chart as a means to identify notable learning instances.

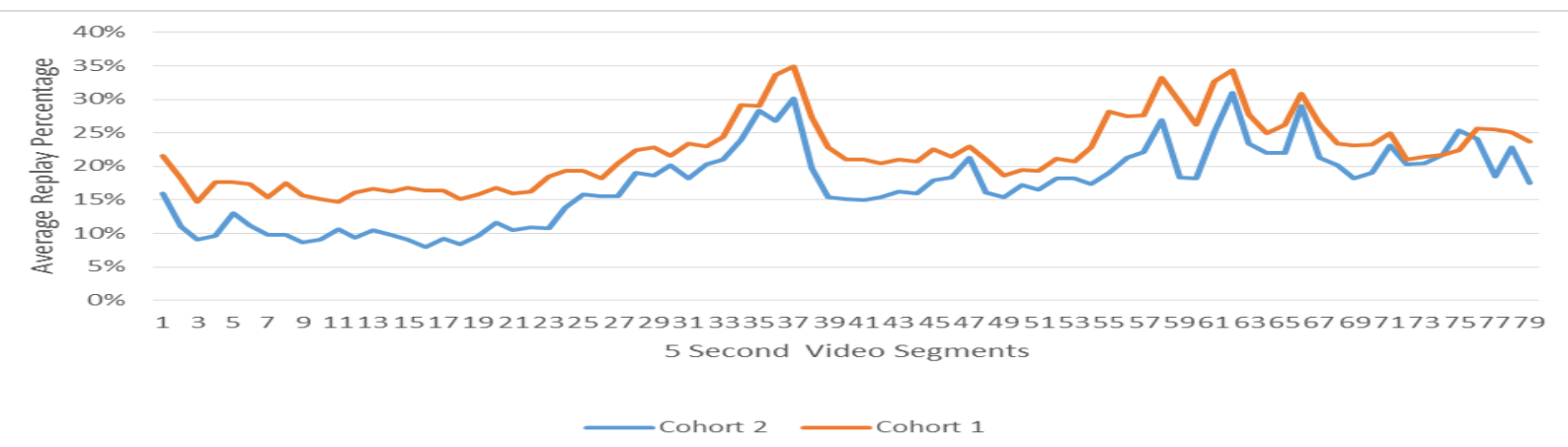

Figure 2. Comparison of Replay-Peak Attention Charts (Cohorts 1 \& 2, Unit 2, Video 2)

The third quantitative phase of the analysis process examined the second cohort of the MOOC. We used the replay-peak attention chart for identifying notable learning instances. Furthermore, following Guo et al. (2014), we labeled the video segments and added a new category 'Edutainment'. As a secondary goal, this paper evaluated the impact of edutainment on learner attention, as manifested in replay-peaks. Therefore, other conventional content types were grouped 
into one category. The analysis is described in the Results Section, followed by discussion of the findings.

\section{Results}

We analyzed Cohort 2 of the "Negotiation Management" MOOC, which contains eight units. The first unit was excluded because first units are frequently accessed by people who are curious about some aspect of a MOOC, but who are not necessarily intending to actually learn the entire course. The analysis started with 32 videos, having a total length of 179 minutes. There were 895 short 5second segments, out of which, 87 segments were identified as replay-peaks. However, Unit 8, which is the last unit of the MOOC, is an outlier. Thus, Unit 8 was excluded. Table 1 presents the final sample.

Table 1. The Short Video Lectures Sample

\begin{tabular}{|l|c|}
\hline Measure & No. \\
\hline Number of Short Video Lectures & 29 \\
\hline Total Analyzed Video Length (Minutes) & 169 \\
\hline Total Number of 5-Second Video Segments & 845 \\
\hline Total Number of Replay-Peaks & 81 \\
\hline
\end{tabular}

Table 2. Descriptive Statistics of the Short video Lectures Sample (Number of Videos $=29)$

\begin{tabular}{|l|c|c|c|c|c|}
\hline Measure & Average & SD & Median & Min & Max \\
\hline Video Length (minutes: seconds) & $5: 49$ & $1: 34$ & $6: 35$ & $2: 00$ & $7: 40$ \\
\hline Viewers 30 Seconds from Beginning & 135.5 & 61.3 & 119 & 58 & 309 \\
\hline Viewers 30 Seconds before Ending & 111.9 & 57.4 & 92 & 40 & 287 \\
\hline Retention Rate & $81 \%$ & $9 \%$ & $81 \%$ & $58 \%$ & $94 \%$ \\
\hline Number of Segment Replays & 19.8 & 11.0 & 17.5 & 7.0 & 51.4 \\
\hline $\begin{array}{l}\text { Replay Percentage } \\
\text { (Out of Total Number of Segment Viewers) }\end{array}$ & $17 \%$ & $7 \%$ & $15 \%$ & $7 \%$ & $56 \%$ \\
\hline Total Replay-Peaks & 2.8 & 1.3 & 3.0 & 0.0 & 5.0 \\
\hline Conventional Content Replay-Peaks & 2.8 & 1.3 & 3.0 & 0.0 & 5.0 \\
\hline Edutainment Replay-Peaks & 0 & 0 & 0 & 0 & 0 \\
\hline
\end{tabular}

Table 2 presents the descriptive statistics of the sample. The MOOC videos have an average of $81 \%$ retention rate. Figure 3 further demonstrates that there is negligible attrition: It starts with 267 viewers, some of them leave sporadically. So, toward the end of the short video, which lasts about seven minutes, there are 232 viewers. Hence, the retention rate of that video is $87 \%$. Figure 4 presents the replay-peak attention chart of the same video shown in Figure 3. This video has five replay-peaks. When we observe these figures together, it is evident that the learning material does not contain difficult content, because although difficult content is usually replayed and may be identified as a replay-peak, such a peak is generally followed by an immediate mass attrition of viewers. Additional qualitative examination of the identified replay-peaks corroborated that these 
are indeed, notable learning instances. Regarding the replay-peaks type, the data in Table 2 shows zero average edutainment replay peaks in the examined 29 videos, none of the 81 identified replaypeaks occurred in the edutainment part of the video lectures.

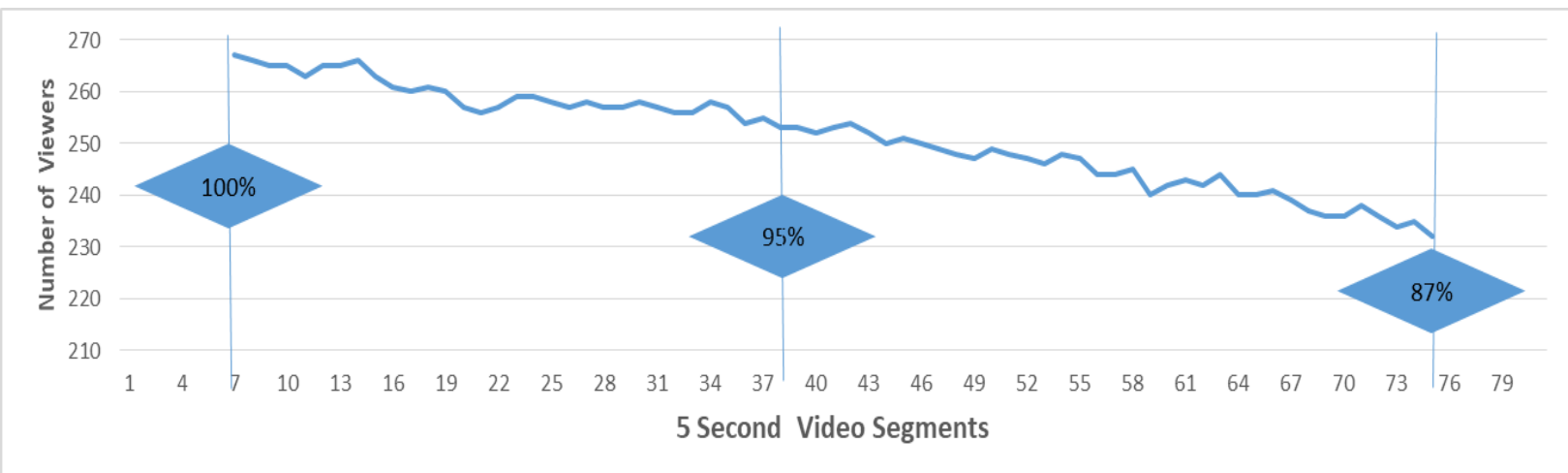

Figure 3. A Retention Curve (Based on data from: Cohort 2, Unit 2, Video 2)

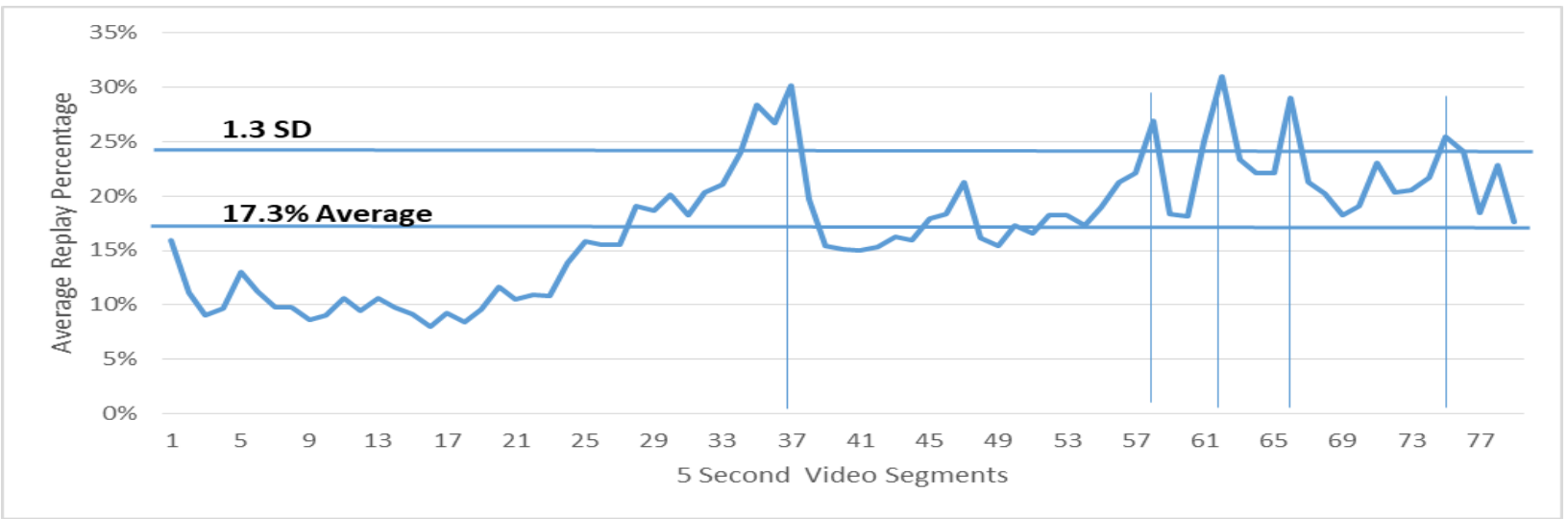

Figure 4. A Replay-Peak Attention Chart (Based on data from: Cohort 2, Unit 2, Video 2)

\section{Discussion}

The replay-peak attention chart, which is based on the control chart concept (Deming, 1982, 2018; Shewhart, 1926, 1986), follows the criteria of effective performance measures (Geri \& Ronen, 2005): it is understandable, relevant, simple, easy to apply, and based on existing data. This pioneering conceptualization of the replay-peak attention chart has several theoretical and practical implications. The theoretical formulation of a replay-peak provides an important performance measure, which may be implemented on a large scale by adopting it into existing Video-onDemand (VOD) players. The defined boundaries (i.e., 1.3 standard deviations above the average, as the lower boundary of replay-peaks), should be refined in future research.

Another novel aspect of this study is the focus on edutainment and its impact on replays. Our findings indicated that the edutainment segments did not contain replay-peaks at all. It is wellknown that people return to games. Sitcoms as edutainment may be different. We suggest that these sitcom episodes are examples that naturally students remember as anecdotes and may help 
them to deepen their intuitive understanding of the learning content. Therefore, future research should further investigate how sitcoms as edutainment affect the long-term learning impact of this type of courseware.

The replay-peak attention chart should be further examined empirically under similar, as well as different conditions than those of the current research. Specifically, since the "Negotiation Management" MOOC is unique, both in its high retention rate and the lack of difficult content, these two conditions should be examined separately, and together. Furthermore, the edutainment aspect of the examined MOOC is not prevalent and requires a relatively high investment. The effectiveness of the replay-peak attention chart should be re-examined in learning environments that do not contain notable edutainment content, or with additional types of edutainment, such as gamification. The replay-peak performance measure may also be used to identify important learning content that did not reach the expected higher levels of attention of learners. Thus, instructors may intervene and direct student attention to these neglected content segments. Such intervention (e.g., quiz questions or short summaries), once they are added to the learning environment, may automatically improve learning of the following cohorts. This is another promising aspect for further research.

Learning Analytics (LA) provide objective empirical evidence on human behavior in real-life settings. Nonetheless, a recognized limitation of LA is that it does not answer directly the question of why people behave in a certain way. The Learning Analytics Performance Improvement Design (LAPID) framework, suggested by Winer and Geri (2019) was designed to address the "why" question. It provides instructors with guidelines to design and decipher actual learning. The replaypeak attention chart may be regarded as a new LAPID based dashboard that is dedicated to the analysis of video content. Answering the "why" question always requires complementing the automated visual data dashboards with the active evaluation of course instructors. Therefore, future research should examine how to effectively implement the replay-peak attention chart. This involves developing methodologies for analyzing the information, as well as designing training for instructors.

There may be several reasons for replaying a certain segment within an online video lecture. The replay-peak attention chart reflects learner engagement. Naturally, we expect that replays caused by sporadic lack of learner attention will fluctuate randomly during the course of the lecture and would not trigger a replay-peak. Contrarily, a reply-peak may not necessarily represent a notable learning instance. Based on the quantitative signals provided by the reply-peak attention chart dashboard, instructors can critically examine why these specific segments were replayed by their students. Moreover, they can evaluate why specific highly significant segments did not meet the intended levels of a replay-peak. Such a qualitative analysis should be guided by the original pedagogical intent (Lockyer et al., 2013) of the instructors when they designed the video. This comparison of pedagogical intent with actual learner behavior may help instructors develop interventions to improve their future learning design.

Further studies may consider using the replay-peak attention chart to examine the effectiveness of interventions in controlled lab experiment settings. However, internal and external motivations of the participants to learn a particular content may affect their attention level. Therefore, participant motivations should be considered when designing such experiments. 
Learner motivation (Oyserman, 2015) is an important consideration whenever the replay-peak attention chart is used, whether for practice or research. Specifically, the MOOC analyzed in this paper, teaches negotiation management. Individuals are expected to be highly motivated to learn negotiation management skills, as these are relevant to multiple aspects of their life. However, further research is needed to examine how to effectively use the replay-peak attention chart when some learners are not aware of the importance of certain topics.

The replay-peak attention chart was conceptualized in the context of higher education and lifelong learning. In the current knowledge-driven economy (Russ, 2017), lifelong learning is necessary both for the well-being of individuals and for sustaining wealth of organizations, countries, and communities. The replay-peak attention chart may serve as a means to improve the design of online video lectures for professional training by firms, government agencies, and other organizations.

Careful consideration should be taken regarding who may see the replay-peak attention chart and its related information, i.e., either detailed data that was used to construct a specific chart, or certain performance measures that were calculated by the LA algorithm. Winer and Geri (2019) raised concerns regarding the potential harmful effects of Learning Analytics Dashboards (LAD). The LAPID framework considers the different organizational perspectives of various stakeholders (e.g., instructors; academic management; administrative functions). A tailored LAD for every type of stakeholders would help them to improve the performance of the organization as a whole (Winer \& Geri, 2019). Future research should explore how to design user-driven versions of replay-peak attention charts performance measures. The LAPID designers should consider why, when, and how potential stakeholders are required to get access privileges to every specific LAD. For instructors, this practice mitigates the specific ethical concerns associated with exposure to their students' personal data, as well as LA general ethical challenges.

An important issue that should be further examined is the timing of the activation of the replaypeak attention chart analysis. During the semester, monitoring the replay-peak attention chart may enable instructors to intervene and perhaps to improve student achievements. Alternatively, an analysis after the end of the semester, as part of a reflection-on-action of instructors, may provide insights for improving future cohorts of the same course, or other courses. Until the replay-peak attention chart is carefully examined and further substantiated, we suggest self-limiting and cautious interventions. Reaching effective guidelines for the design of effective video lectures requires future research on the learning outcomes of systematic intervention schemes and practices.

\section{Conclusion}

This paper developed the replay-peak attention chart as a performance measurement instrument for improving learning design. Drawing on the control chart concept, which is used for statistical process control in operations management, the paper defined the replay-peak as a performance measure of learner's attention. Moreover, this paper designed the replay-peak attention chart as a visual heuristic tool for instantly identifying notable learning instances. Identifying these learning instances, which are sometimes tacit, may help instructors and designers to improve learning via online video lectures. The analysis of the Negotiation Management MOOC served as a proof-ofconcept for the presentation of the replay-peak attention chart. Future research will explore the 
feasibility of using it as an effective instrument for video content development and teaching. This dynamic descriptive performance measurement is simple and understandable. Therefore, the replay-peak attention chart has a promising potential to improve the emerging field of designing effective video lectures.

\section{References}

Aguayo, R. (1991). Dr. Deming: The American who taught the Japanese about quality. Simon and Schuster.

Coghlan, D. (2019). Doing action research in your own organization. SAGE Publications.

Davenport, T. H., \& Beck, J. C. (2001). The attention economy: Understanding the new currency of business. Harvard Business School Press.

Deming, W. E. (1982). Out of the crisis. $1^{\text {st }}$ Ed. MIT Press.

Deming, W. E. (2018). Out of the crisis. MIT Press.

Ellis, T. J., \& Levy, Y. (2009). Towards a guide for novice researchers on research methodology: Review and proposed methods. Issues in Informing Science \& Information Technology, 6, 323-337. https://doi.org/10.28945/1062

Ferguson, R. (2012). Learning analytics: Drivers, developments and challenges. International Journal of Technology Enhanced Learning, 4(5/6), 304-317. https://doi.org/10.1504/ IJTEL.2012.051816

Geri, N., \& Geri, Y. (2011). The information age measurement paradox: Collecting too much data. Informing Science: The International Journal of an Emerging Transdiscipline, 14, 47-60. https://doi.org/10.28945/1356

Geri, N., \& Ronen, B. (2005). Relevance lost: The rise and fall of activity-based costing. Human Systems Management, 24(2), 133-144.

Geri, N., Winer, A., \& Zaks, B. (2017). Challenging the six-minute myth of online video lectures: Can interactivity expand the attention span of learners? Online Journal of Applied Knowledge Management, 5(1), 101-111. https://doi.org/10.36965/OJAKM.2017.5(1)101-111

Guo, P. J., Kim, J., \& Rubin, R. (2014). How video production affects student engagement: An empirical study of MOOC videos. Proceedings of the first ACM conference on Learning@scale conference, 41-50. https://doi.org/10.1145/2556325.2566239

Henderikx, M. A., Kreijns, K., \& Kalz, M. (2017). Refining success and dropout in massive open online courses based on the intention-behavior gap. Distance Education, 38(3), 353-368. https://doi.org/10.1080/01587919.2017.1369006

Hevner, A. R. (2007). A three cycle view of design science research. Scandinavian Journal of Information Systems, 19(2), 87-92. 
Jørnø, R. L., \& Gynther, K. (2018). What constitutes an 'actionable insight' in learning analytics? Journal of Learning Analytics, 5(3), 198-221. https://files.eric.ed.gov/fulltext/ EJ1199921.pdf

Kalz, M., Kreijns, K., Walhout, J., Castaño-Munoz, J., Espasa, A., \& Tovar, E. (2015). Settingup a European cross-provider data collection on open online courses. The International Review of Research in Open and Distributed Learning, 16(6). https://doi.org/10.19173/ irrodl.v16i6.2150

Koohang, A., Paliszkiewicz, J., Nord, J. H., \& Ramim, M. (2014). Advancing a theoretical model for knowledge construction in e-learning. Online Journal of Applied Knowledge Management, 2(2), 12-25. http://www.iiakm.org/ojakm/articles/2014/volume2 2 2/ OJAKM Volume2 2pp12-25.pdf

Kopolovich, O. (forthcoming, 2020). Learning soft skills in the digital age: Challenges and insights from development and teaching 'Negotiation Management' MOOC. Online Journal of Applied Knowledge Management.

Larrabee Sønderlund, A., Hughes, E., \& Smith, J. (2019). The efficacy of learning analytics interventions in higher education: A systematic review. British Journal of Educational Technology, 50(5), 2594-2618. https://doi.org/10.1111/bjet.12720

Levy, Y. (2007). Comparing dropouts and persistence in e-learning courses. Computers \& Education, 48(2), 185-204. https://doi.org/10.1016/j.compedu.2004.12.004

Li, N., Kidzinski, L., Jermann, P., \& Dillenbourg, P. (2015). How do in-video interactions reflect perceived video difficulty? Proceedings of the European MOOCs Stakeholder Summit, 112-121. https://infoscience.epfl.ch/record/207968

Lockyer, L., Heathcote, E., \& Dawson, S. (2013). Informing pedagogical action: Aligning learning analytics with learning design. American Behavioral Scientist, 57(10), 14391459. https://doi.org/10.1177/0002764213479367

Makarius, E. E. (2017). Edutainment: Using technology to enhance the management learner experience. Management Teaching Review, 2(1), 17-25. https://doi.org/10.1177/2379298116680600

Martin, L., Mills, C., D’Mello, S. K., \& Risko, E. F. (2018). Re-watching lectures as a study strategy and its effect on mind wandering. Experimental Psychology, 65(5), 297-305. https://doi.org/10.1027/1618-3169/a000412

Moe, R. (2015). OER as online edutainment resources: A critical look at open content, branded content, and how both affect the OER movement. Learning, Media and Technology, 40(3), 350-364. https://doi.org/10.1080/17439884.2015.1029942

Mor, Y., Ferguson, R., \& Wasson, B. (2015). Learning design, teacher inquiry into student learning and learning analytics: A call for action. British Journal of Educational Technology, 46(2), 221-229. https://doi.org/10.1111/bjet.12273 
Mor, Y., \& Winters, N. (2007). Design approaches in technology-enhanced learning. Interactive Learning Environments, 15(1), 61-75. https://doi.org/10.1080/10494820601044236

O'Flaherty, J., \& Phillips, C. (2015). The use of flipped classrooms in higher education: A scoping review. The Internet and Higher Education, 25, 85-95. https://doi.org/10.1016/j.iheduc.2015.02.002

Oyserman, D. (2015). Identity-based motivation. In R. A. Scott \& S. M. Kosslyn (Eds.), Emerging trends in the social and behavioral sciences: An interdisciplinary, searchable, and linkable resource. Wiley Online Library. https://doi.org/10.1002/9781118900772.etrds0171

Okan, Z. (2003). Edutainment: Is learning at risk? British Journal of Educational Technology, 34(3), 255-264. https://doi.org/10.1111/1467-8535.00325

Pasquale, F. (2015). The black box society. Harvard University Press.

Rienties, B., \& Toetenel, L. (2016). The impact of learning design on student behaviour, satisfaction and performance: A cross-institutional comparison across 151 modules. Computers in Human Behavior, 60, 333-341. https://doi.org/10.1016/j.chb.2016.02.074

Ronen, B., \& Pass, S. (2007). Focused operations: Achieving more with existing resources. John Wiley and Sons.

Ronen, B., Pliskin, J. S., \& Pass, S. (2006). Focused operations management for health services organizations. John Wiley \& Sons.

Russ, M. (2017). The trifurcation of the labor markets in the networked, knowledge-driven, global economy. Journal of the Knowledge Economy, 8(2), 672-703. https://doi.org/10.1007/s13132-016-0434-0

Shewhart, W. A. (1926). Quality control charts. The Bell System Technical Journal, 5(4), $593-$ 603. https://doi.org/10.1002/j.1538-7305.1926.tb00125.x

Shewhart, W. A. (1986). Statistical method from the viewpoint of quality control. Dover.

Simon, H. A. (1996). The sciences of the artificial. MIT Press.

Taylor, M., Vaughan, N., Ghani, S. K., Atas, S., \& Fairbrother, M. (2018). Looking back and looking forward: A glimpse of blended learning in higher education from 2007-2017. International Journal of Adult Vocational Education and Technology, 9(1), 1-14. https://doi.org/10.4018/IJAVET.2018010101

Van Riper, A. (2011). Learning from Mickey, Donald and Walt: Essays on Disney's edutainment films. McFarland.

Winer, A., \& Geri, N. (2019). Learning analytics performance improvement design (LAPID) in higher education: Framework and concerns. Online Journal of Applied Knowledge Management, 7(2), 41-55. https://doi.org/10.36965/OJAKM.2019.7(2)41-55 
Woodall, W. H. (2000). Controversies and contradictions in statistical process control. Journal of Quality Technology, 32(4), 341-350. https://doi.org/10.1080/00224065.2000.11980013

Woodall, W. H., \& Faltin, F. W. (2019). Rethinking control chart design and evaluation. Quality Engineering, 31(4), 596-605. https://doi.org/10.1080/08982112.2019.1582779

\section{Authors Biographies}

Nitza Geri is an Associate Professor at the Open University of Israel, Department of Management and Economics. She is a board member of the Research Center for Innovation in Learning Technologies, and served as Head of the center (2012-2018). Nitza holds a B.A. in Accounting and Economics and a Ph.D. in Technology and Information Systems Management from Tel-Aviv University. She is a CPA (Israel) with over 12 years of business experience. Nitza is on the leadership team of the International Institute for Applied

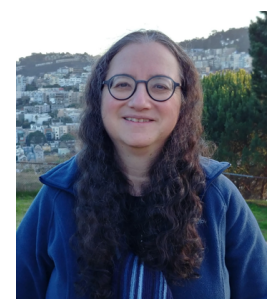
Knowledge Management (IIAKM). Her research interests focus on the value of information and knowledge: strategic information systems, information economics, attention economy, knowledge management, value creation, Theory of Constraints, and effectiveness of e-learning. Personal site: http://www.openu.ac.il/en/personalsites/NitzaGeri.aspx

Orna Kopolovich is a Senior lecturer, at Holon Institute of Technology (H.I.T.), Faculty of Technology Management and Faculty of Instructional Technologies. She is member of the Board of Trustees and of the Supreme Academic Council, at H.I.T, Likewise the head of HIT's Center for Negotiation Management and Business Innovation. Orna developed a Massive Open Online Course (MOOC) on Negotiation Management (2018). Orna holds a B.A. in Political Science and Sociology (1992); LL.B. (1997); LL.M (2005) and Licensed Professional

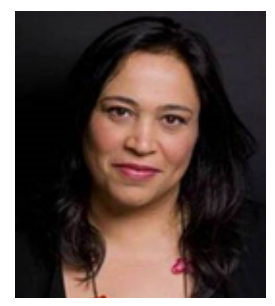
Mediation (2003). All from Bar-Ilan University, Israel. Her Master's Thesis in Conflict Management and Negotiation was titled 'The contacts between conflict management style, culture and negotiators similarity'. Advocate, member of The Israel Bar Association (since 1997). Personal site: https://www.hit.ac.il/en/faculty_staff/Orna_Kopolovich

Amir Winer Heads the Learning Analytics Initiative and the Interactive Courseware unit at the Open University of Israel. He served as a special digitation consultant for Israel's Ministry of Education and led the design of Israel's standard for developing K12 Digital Textbooks. Prior to joining the Open University of Israel, Amir was Head of R\&D at the Center for Futurism in Education at Ben Gurion University. Amir is a $\mathrm{PhD}$ student at Bar Ilan University and holds an MA in Psychology and a BA in Cognitive Science, both

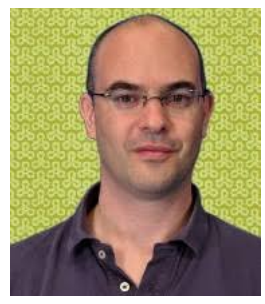
from Ben-Gurion University. 